\title{
Pathway mapping of airflow delivery to the production areas in underground mine ventilation systems
}

\author{
GG Li Natural Resources Canada, Minerals and Metals Sector, CanmetMINING, Canada \\ SG Hardcastle Natural Resources Canada, Minerals and Metals Sector, CanmetMINING, Canada
}

\begin{abstract}
Pathway mapping is a new tool in the 3D-CANVENT ventilation software to track potential air pathways in complex mine ventilation systems and help in determining the pressure differences to deliver the required airflow to underground workplaces. After a ventilation model is established, a structure tree of the ventilation system can be formed from the branch series based on the ventilation parameters, locations of fans and regulators, and the airflow state as obtained from mine ventilation simulation. In order to find the unique pathway to each workplace, strict rules must be set to respect the structure tree and the priority of different fans in operation. The pathway tracking system provides a graphic interface with multi-functional tools and data sheets for generating and manipulating the structure tree and tracking the airflow pathways to different locations in the mine. It can be used in designing and managing the advanced mine ventilation systems, such as the ventilation on demand (VOD) systems, and to efficiently deliver the fresh air to the production areas in deep mines.
\end{abstract}

\section{Introduction}

A large underground mine ventilation system can consist of hundreds of airways and multiple fans that provide fresh air to production workings. It is important, and at the same time challenging, to optimise a large and complex mine ventilation system in order to reduce the energy consumption and hence the potential environmental impact. Because the effect of fans and control devices (doors/regulators) are interconnected, any change in the state of either can cause major airflow redistribution throughout the network. The purpose of the pathway mapping is to identify all possible airway paths, through which the required volume of fresh air can be efficiently delivered to the production workings, and to determine the driving pressure of the associated primary and secondary fans.

After a ventilation model is established, a structure tree of the ventilation system can be formed from the branch series based on the ventilation parameters, locations of fans and control devices, and airflow state obtained from mine ventilation simulation. The unique pathway to each workplace is determined through strict rules set respecting the structure tree of the network and the priority of different fans in operation. This new tool for pathway mapping has been developed and incorporated in the 3D-CANVENT ventilation software (Li et al. 2009), to perform advanced analysis for deep and complex mine ventilation systems, which would be required for the mine-wide VOD systems (Hardcastle et al. 2006). The pathway tracking system provides a graphic interface and interactive data sheets for viewing and manipulating the structure tree, and tracing the airflow pathways delivering air to different locations in the mine.

This paper presents the methodology and procedure of the airflow pathway mapping and its integration in mine ventilation modelling. An example of a mine ventilation system is used to demonstrate the capability of the software in forming the structure tree, and tracking the airflow pathways from a surface intake to specified underground workplaces. 


\section{Branch series and ranks}

A branch series consists of a number of branches that connect end to end without breaks. Therefore, the air quantity passed through a branch series is the same for all the branches included. The resistance of a branch series is the total resistance of all included airway branches. The branch series can be used to form the structure tree, which would technically represent the original ventilation system if the branch parameters and ventilation controls (fans and regulators, etc.) are properly simulated.

In order to identify the stages of air paths, e.g. from intake to workplaces on various levels and back to exhaust, each branch of airways in a ventilation system must be classified to a specific rank. For a typical mine ventilation network, the intake branches (including the intake plenum and shaft) are always classified as rank number 1 , if the starting branch is set to intake in the ventilation model. The branches connected to the intake shaft from the top level are classified as rank number 2 . The branches going to production areas and workplaces on the top level and the branches connected to the intake shaft from the second level are rank 3. Further down, the branches connected to the intake shaft from the third level are rank 4 . The classification continues following the flow directions in the system until all branches are sorted and assigned with rank numbers.

When started from the intake(s), the exhaust shaft and associated fan plenum branches always have the highest rank number. The process can be started in reverse direction from exhaust or from any branch specified, such as a fan branch. The pathway mapping dialog form (Figure 1) lets the user choose the starting branches and input the parameters required.

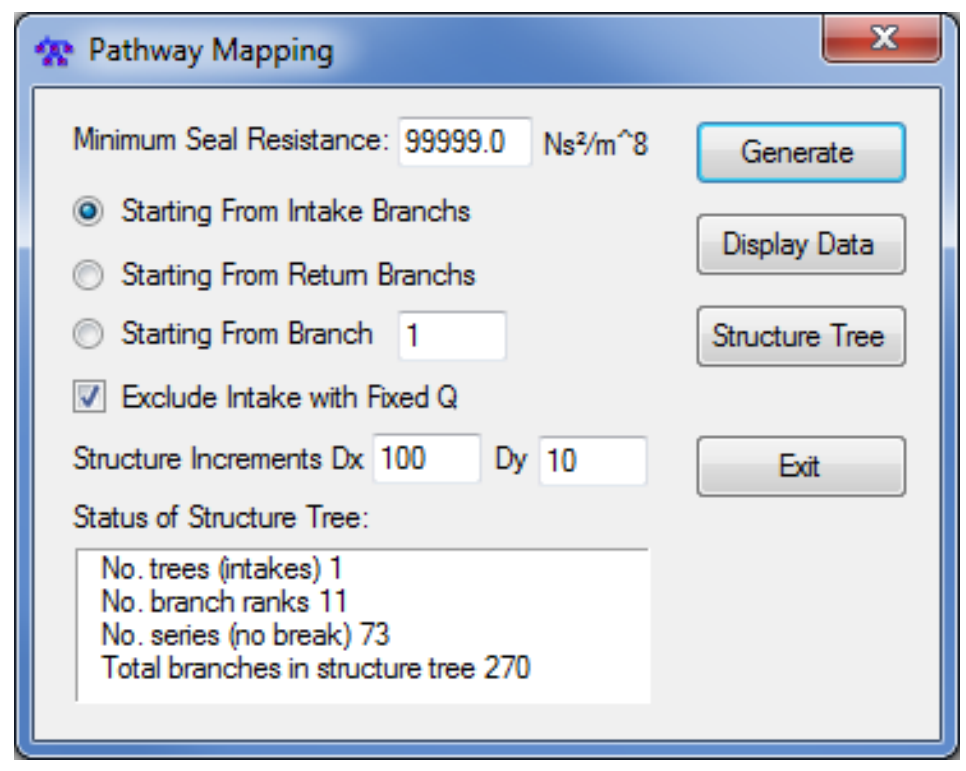

\section{Figure 1 Structure tree settings in pathway mapping}

Ventilation controls (doors/regulators) and airway resistances affect the pathways of airflow delivery to expected workplaces. In extreme cases, the airways are sealed or specified with high resistances, e.g. $99,999 \mathrm{Ns}^{2} / \mathrm{m}^{8}$. These branches will be excluded from the branch series and the structure tree.

The ventilation model must be simulated through ventilation network analysis (McPherson 1993) before attempting to generate the branch series and the structure tree of the system. The information of branch series can be displayed in a spreadsheet by clicking the 'Display Data' button on the dialog form.

\section{Structure tree of a ventilation system}

The structure tree is actually a simplified network of the original ventilation system. It consists of branch series associated with ventilation parameters, fixed quantities, fans and regulators. Therefore, the structure 
tree represents the ventilation system in terms of ventilation parameters, pressure changes and airflow state throughout the network.

In order to visually display the structure tree of a ventilation system, the junction nodes that define the branch series must be assigned new coordinates. For better viewing, the structure tree can be plotted from top to bottom describing the airflow entering from the intake and returning to the exhaust of the ventilation network. The rank numbers of branch series can be used to determine the locations of junction nodes in a $2 \mathrm{D} \mathrm{XY}$ coordinate system. The junction coordinates would be formed following the rule that the branch series with same rank number are located in the same elevation or height ( $Y$ coordinate); and, for each split along the pathway, the branch series with higher rank number (further away from the intake) are extended on both sides (X coordinates) of the lower rank branch.

For a simple ventilation network, the structure tree generated following the rule is manageable. However, when many branches join the return shafts in a complex ventilation system, overlaps of the branch series from different levels always occur in the lower part of the structure tree. For this reason, a group of editing tools have been provided in the pathway mapping interface to help users modify the structure tree so that the ventilation system can be properly interpreted and the pathways to the concerned mine locations easily tracked.

Figure 2 is a sample network with 17 branches, 13 junctions and two fans. The structure tree in Figure 3 was generated after the ventilation model was simulated. Each line segment in the structure tree represents a branch series denoted by the number on it. The thickness and colour of the line indicate the rank number of the branch series - the thicker the lower rank number. The branch series information that describes the structure tree is shown in Figure 4.

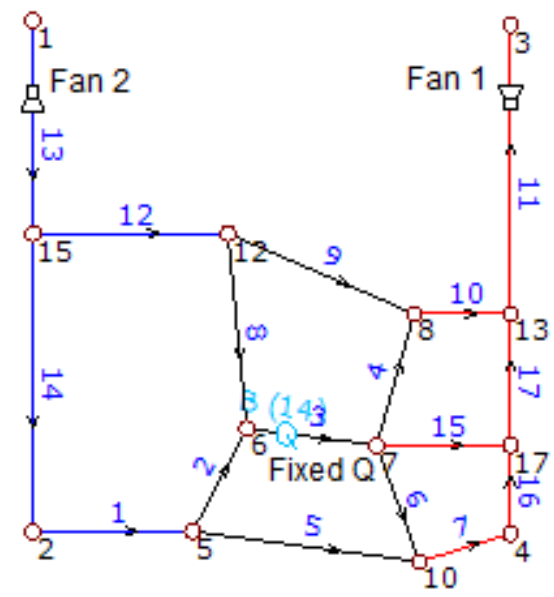

\section{Figure 2 A sample vent network}

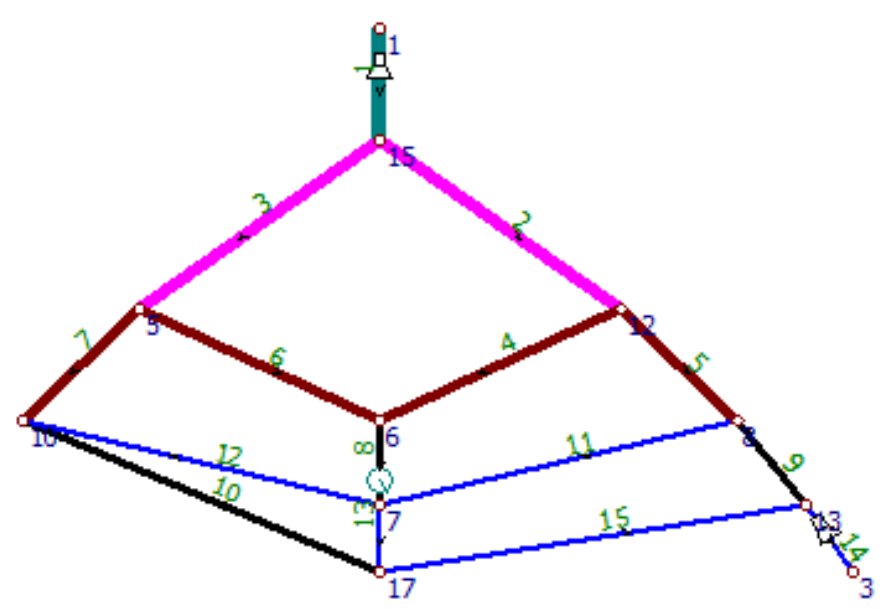

Figure 3 Structure tree of the sample network 


\begin{tabular}{|c|c|c|c|c|c|c|c|c|c|c|c|}
\hline \multicolumn{9}{|c|}{ Te Pathway Sample.mvf - 3D-CANVENT [Pathway Structure Data] } & \multicolumn{3}{|c|}{\begin{tabular}{|l|l|l|}
$口$ & 口 & $x$ \\
\end{tabular}} \\
\hline $\begin{array}{c}\text { Series } \\
\text { No. }\end{array}$ & $\begin{array}{c}\text { Rank } \\
\text { No. }\end{array}$ & $\begin{array}{l}\text { Sub } \\
\text { Tree }\end{array}$ & $\begin{array}{c}\text { Lower Rank } \\
\text { Branch }\end{array}$ & $\begin{array}{c}\text { First } \\
\text { Junction }\end{array}$ & $\begin{array}{c}\text { Last } \\
\text { Junction }\end{array}$ & $\begin{array}{c}\text { FQR } \\
\text { Control }\end{array}$ & $\begin{array}{l}\text { Resistance } \\
\left(\mathrm{Ns}^{2} / \mathrm{m}^{\wedge} 8\right)\end{array}$ & $\begin{array}{l}\text { Quantity } \\
\left(\mathrm{m}^{3} / \mathrm{s}\right)\end{array}$ & $\begin{array}{l}\text { Pressure } \\
\text { Drop (Pa) }\end{array}$ & $\begin{array}{l}\text { Branches } \\
\text { in Series }\end{array}$ & $\Delta$ \\
\hline 1 & 1 & 1 & 0 & 1 & 1 & Fan 2 & 0.001 & 337.465 & 113.9 & 13 & \\
\hline 2 & 2 & 1 & 13 & 2 & 1 & & 0.004 & 142.139 & 80.8 & 12 & $\equiv$ \\
\hline 3 & & 2 & 13 & 3 & 1 & & 0.002 & 195.326 & 76.3 & 14,1 & \\
\hline 4 & 3 & 1 & 12 & 2 & 1 & & 0.001 & 59.969 & 3.6 & 8 & \\
\hline 5 & & 2 & 12 & 3 & 1 & & 0.002 & 82.17 & 13.5 & 9 & \\
\hline 6 & & 3 & 1 & 2 & 2 & & 0.001 & 90.031 & 8.1 & 2 & \\
\hline 7 & & 4 & 1 & 3 & 1 & & 0.0015 & 105.296 & 16.6 & 5 & \\
\hline 8 & 4 & 1 & 2 & 3 & 1 & Fixed $Q$ & 0.001 & 150.0 & 22.5 & 3 & \\
\hline 9 & & 2 & 9 & 2 & 1 & & 0.005 & 123.236 & 75.9 & 10 & \\
\hline 10 & & 3 & 5 & 2 & 1 & & 0.002 & 125.167 & 31.3 & 7.16 & \\
\hline 11 & 5 & 1 & 3 & 2 & 3 & & 0.001 & 41.067 & 1.7 & 4 & \\
\hline 12 & & 2 & 3 & 3 & 3 & & 0.001 & 19.871 & 0.4 & 6 & \\
\hline 13 & & 3 & 3 & 4 & 2 & & 0.004 & 89.062 & 31.7 & 15 & \\
\hline 14 & & 4 & 10 & 2 & 1 & Fan 1 & 0.001 & 337.465 & 113.9 & 11 & \\
\hline 15 & & 5 & 16 & 3 & 3 & & 0.001 & 214.229 & 45.9 & 17 & + \\
\hline
\end{tabular}

Figure 4 Branch series information of the structure tree

In the branch series data sheet, the resistance and pressure drop represent the total resistance and total pressure difference of the branches included in that series. If the data of branch series is inputted as the branch properties of a new ventilation model, such as the schematic in Figure 3, the simulation results would be the same as obtained from the original network.

In some cases, the structure trees generated by the program are not ideal for representing and interpreting the ventilation systems. For example, in Figure 3 the exhaust branch series 14 would be expected to be plotted in the bottom centre. Moreover, the overlaps of branch series in the structure tree can make it difficult to find a specific production area in the mine and identify the pathway to it. In order to make the structure tree clear and easy to adjust, the schematic of the structure tree can be modified through moving the junctions and/or changing the scales in both directions. The tool box in the pathway mapping interface (Figure 5) provides useful tools for manipulating the structure tree and tracking the pathways to various locations in the mine.

By default, the program generates the coordinates of split junctions from a lower rank branch series and, in most instances, guarantees that the total length of higher rank branch series is the shortest. This would reduce or eliminate some overlaps of branch series. For some ventilation schematics, however, it is necessary to swap or move the junctions in order to form a desirable structure tree. The junction coordinates can also be edited in the junction data sheet alongside the schematic (Figure 5). The 'Update' button is used to refresh the image of the structure tree after the data was modified. The tools on the toolbar and in menu items can be used to pan/zoom the schematic and change the window properties on display. Figure 5 shows the new structure tree after it was modified by relocating junctions 13 and 3 . 


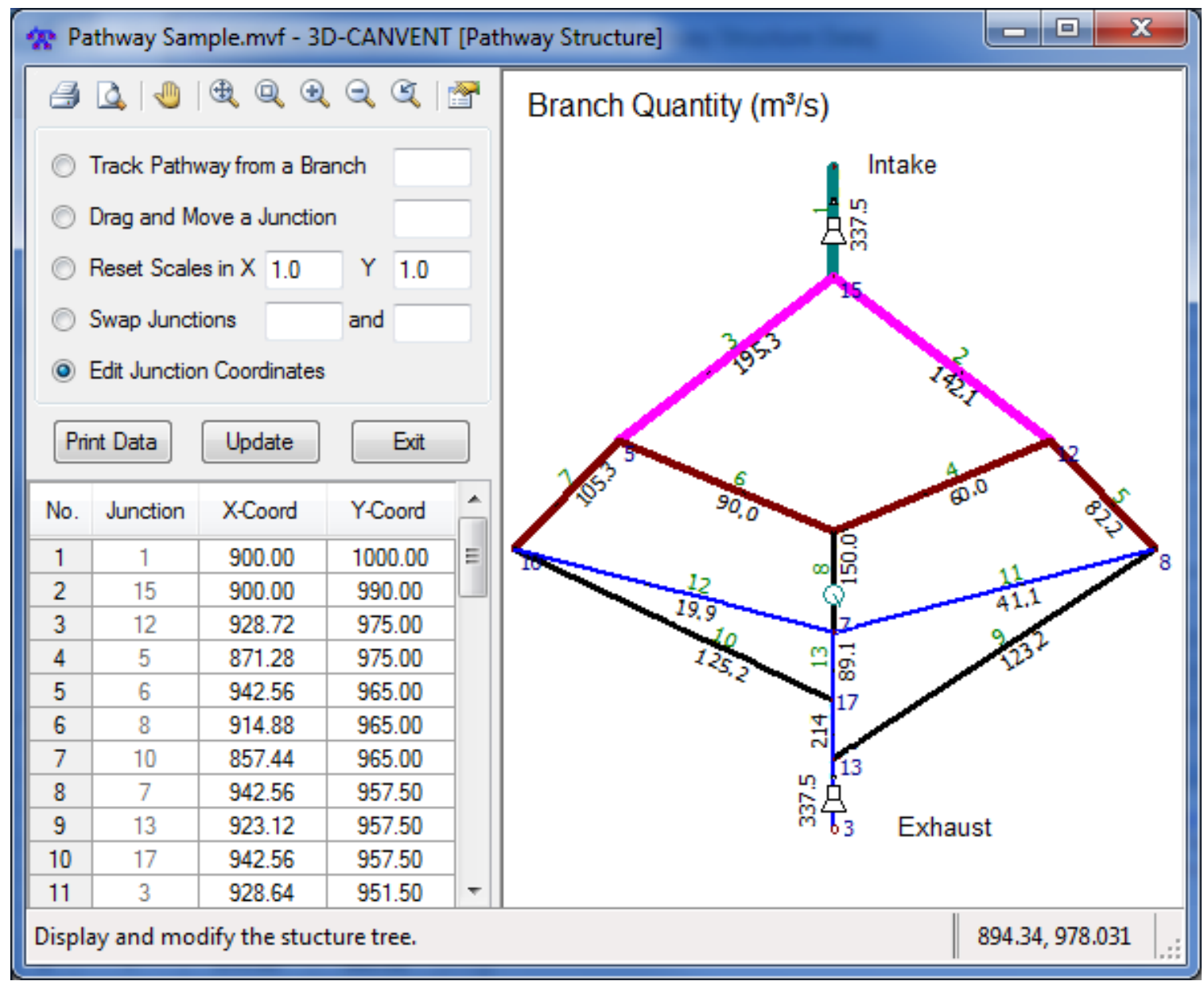

\section{Figure 5 Pathway mapping interface}

An activity-based mine ventilation system (Kocsis et al. 2011), as shown in Figure 6, was used to demonstrate the capabilities of the software in generating the structure tree and removing the overlaps due to the interconnections of branches on different levels. In one scenario, the mine activities were taking place on levels above $1480 \mathrm{~L}$ and fixed air quantities were supplied to the levels below to meet the minimum requirements for air circulation. Two surface fans at the intake and the exhaust airways provided the air power to deliver the airflow required. 


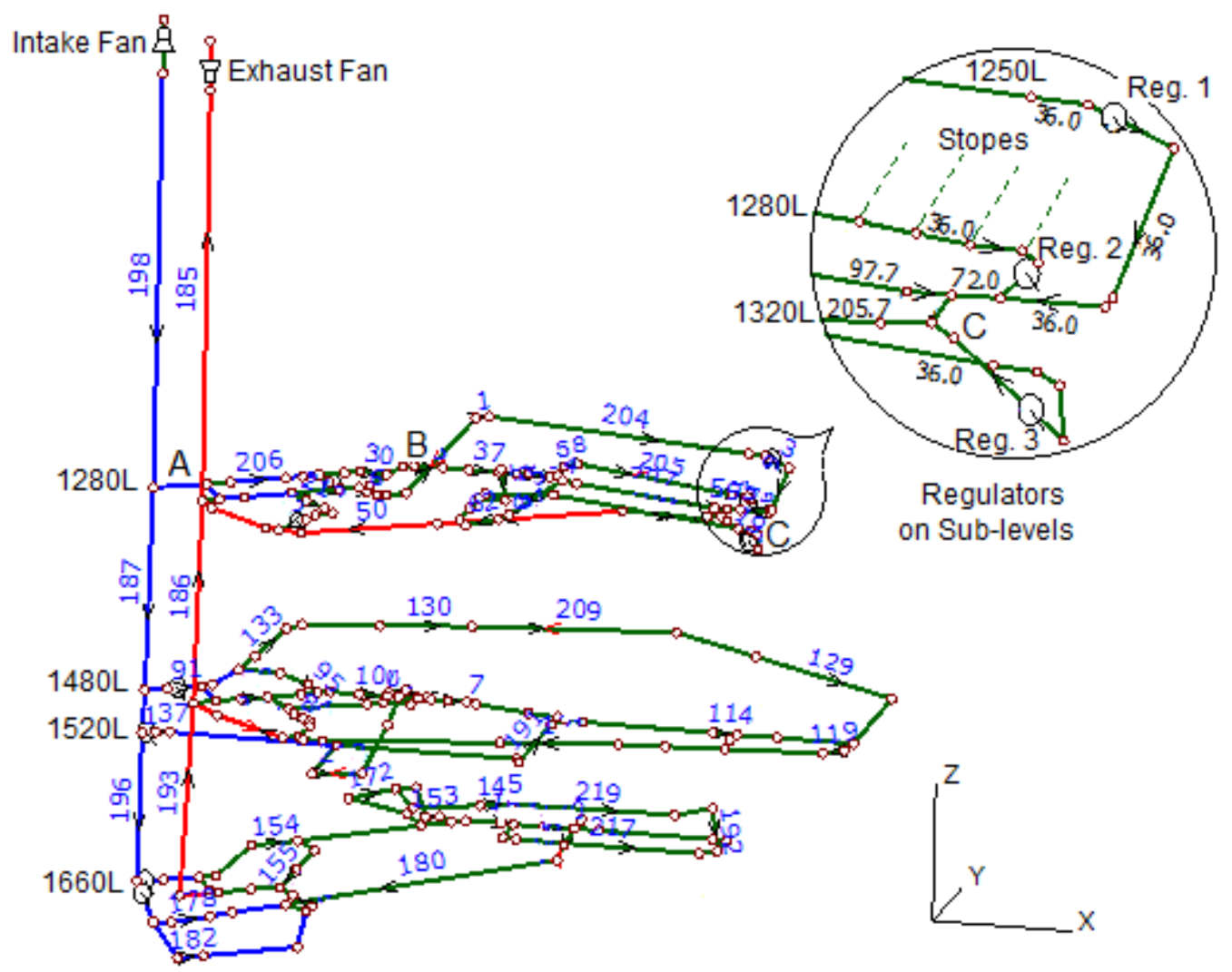

\section{Figure 6 An activity-based ventilation system NRS-PM-0511}

The structure tree in Figure 7 was generated after the ventilation model was simulated. It consisted of 73 branch series that belong to 11 ranks representing the intake and exhaust shafts, the drifts and raises on different levels. The colours and/or line thickness indicated the rank numbers of the branch series. It is easier and clear to track the air pathway for a particular mine location using the structure tree than using the original ventilation schematic.

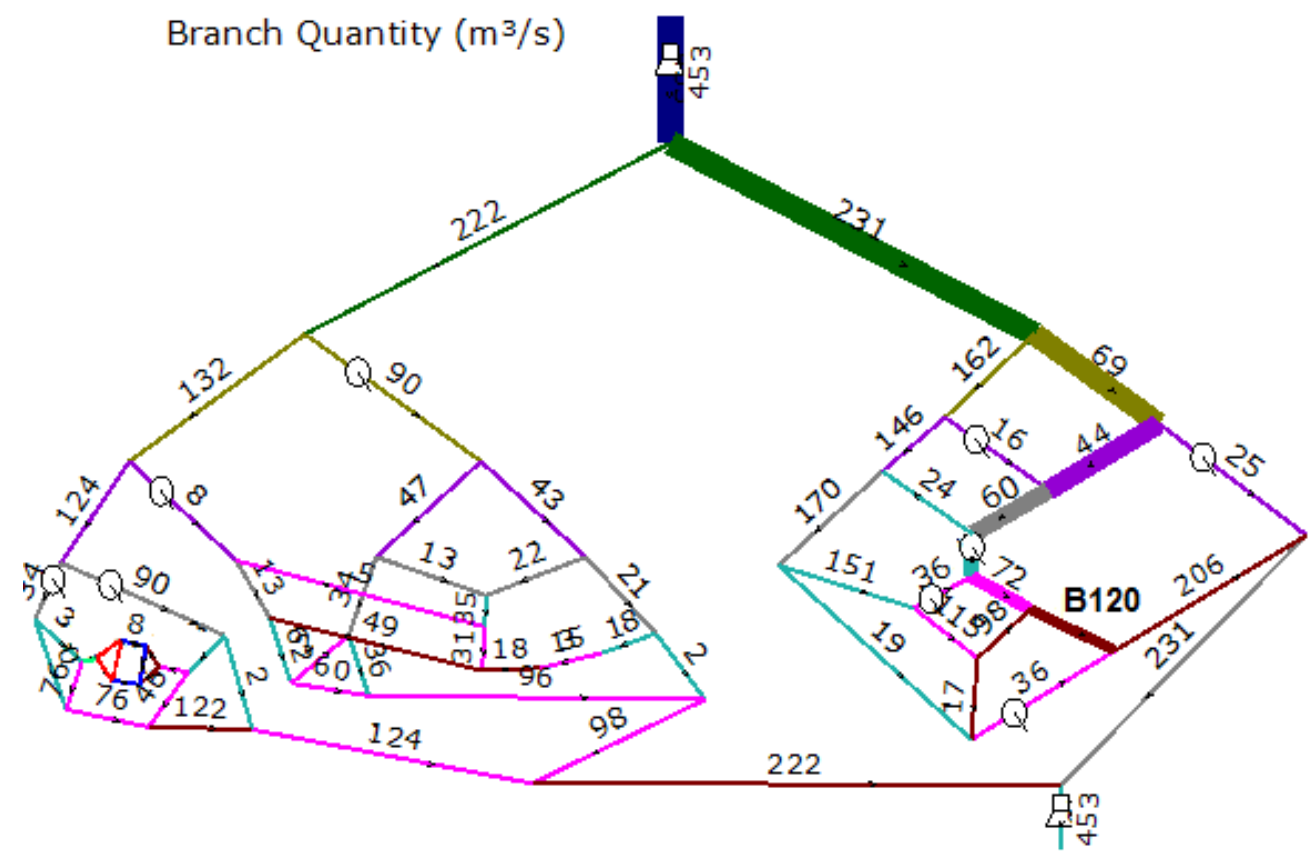

Figure 7 Structure tree of ventilation system NRS-PM-0511 


\section{$4 \quad$ Tracking air pathways to production areas}

In order to find the unique pathway, through which the required airflow is delivered to a specified workplace, the program must examine all possible air paths connected to this location. Strict rules, such as minimum total resistance and priority of nearby fans and controls, have been implemented in the search engine to identify the pathway, so that the branches with minimum resistance and/or fans are included in the pathway.

In generating the branch series and structure tree of a ventilation system, the total resistance of each pathway is always calculated and accumulated from the intake or starting branch. This information is saved instantly and will be used later to search the lowest resistance air pathway to a specified underground mine location. A resistance threshold, e.g. $99,999 \mathrm{Ns}^{2} / \mathrm{m}^{8}$, was set in the beginning to exclude the sealed airways in the structure tree. Ventilation controls such as doors and regulators were included in the branch series and would affect the pathway mapping for certain mine areas.

The lower rank branch associated with each branch series provides a pointer to track the unique pathway from any underground location to the intake or starting branch in opposite direction to the airflow.

A user-friendly pathway tracking tool was developed to identify the pathway of airflow delivery to a specified branch. The program will track and highlight the unique pathway on the structure tree or the ventilation schematic starting from the branch selected, based on the information of branch series and the total resistance of airways. When the pathway mapping is activated from the main interface of 3D-CANVENT, the pathway will be highlighted on the ventilation schematic from the selected branch to the intake.

For ventilation network NRS-MP-0511, the air pathway to a particular location in the mine or a branch in the schematic can be identified using the pathway mapping menu group in the 3D-CANVENT software. Assuming branch 102 on $1320 \mathrm{~L}$ (point $C$ in Figure 6) was selected by clicking the mouse on the branch, the pathway through which the airflow $\left(169.7 \mathrm{~m}^{3} / \mathrm{s}\right)$ was delivered to the location is shown in Figure 8 . The pressure differential required to deliver the air volume was $2.404 \mathrm{kPa}$. The air quantities plotted along the pathway indicate the changes of airflow in each stage of the air path. The pathway delivering the minimum air volume $14.3 \mathrm{~m}^{3} / \mathrm{s}$ to branch 321 on $1660 \mathrm{~L}$ is also shown on the schematic. The total pressure change for this delivery was $2.5 \mathrm{kPa}$.

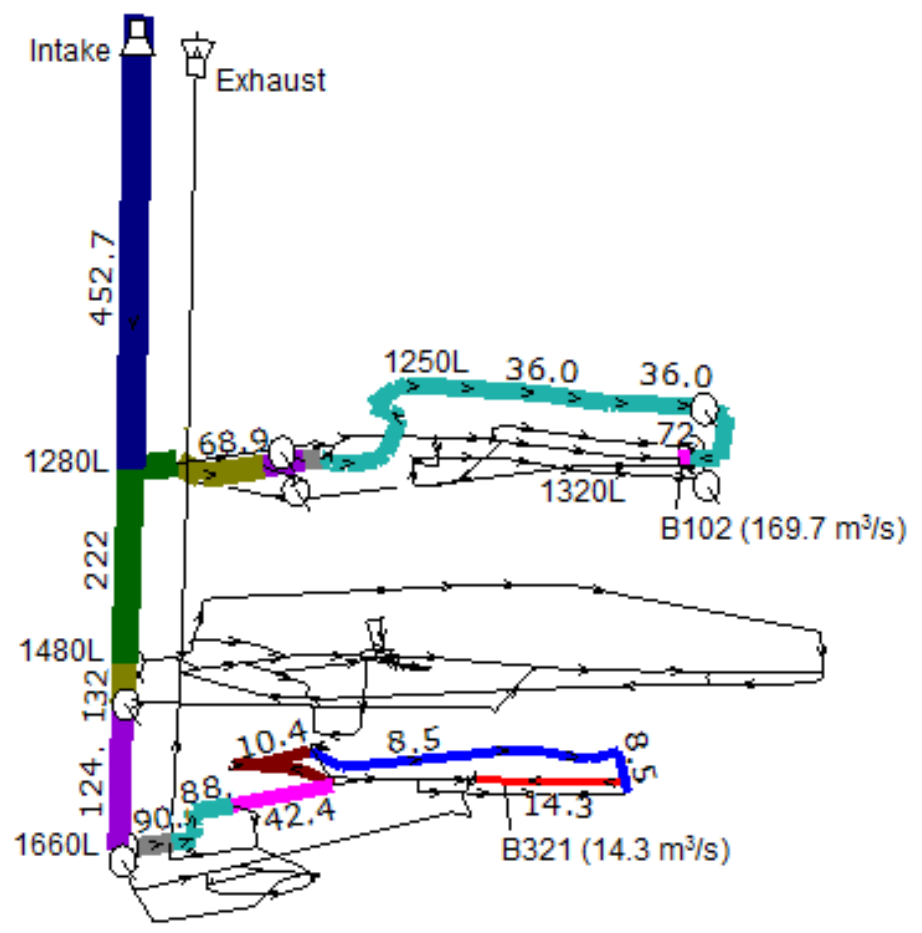

Figure 8 Pathways to underground locations 
The airflow pathways to designated underground mine locations can also be tracked through the structure tree of the ventilation system. The user can enter a branch number or select a branch by clicking the mouse near a branch series on the pathway mapping interface (Figure 5) to track the airflow pathway. For example, the pathway to branch 102 on 1320 L was identified using thick lines in Figure 7.

\section{Conclusion}

A new tool for pathway mapping of airflow delivery to production areas in underground mine ventilation systems has been developed and incorporated in the 3D-CANVENT ventilation software. It includes a structure tree generator and a pathway tracking system, which can be used to track the air pathway to a specified underground mine location and determine the pressure change for delivering the required air volume.

The structure tree of a ventilation system consists of the branch series that represent the air paths in different stages from the intake through underground workings to the exhaust. Since the branch series contain the information about ventilation parameters, branch connections, fans and ventilation control devices (doors and regulators), the structure tree is actually a simplified ventilation system from the original network. It is more clear and straightforward in terms of branch connection and airflow distribution throughout the ventilation system. Therefore, the structure tree can be used to manage and optimise large and complex mine ventilation systems and help track airflow pathways, position fans and regulators, and determine airflow requirements in underground workplaces.

A graphic interface has been developed to display and modify the structure tree after it is formed. The junction coordinates of the branch series are generated following the rule that the structure tree is expanded downward on both sides when branches are split and airflow is diverted. Because the airways from production areas on different levels are usually joined to the exhaust shafts or branches, the structure tree often has overlaps where the airflow returns to the exhaust. The user can modify or repair the structure tree using the tools provided and make it clear and easy to view and track the pathways.

The unique pathway through which the airflow is delivered to an underground location can be identified either on the ventilation schematic or the structure tree by using the 3D-CANVENT pathway tracking system. Airway resistances and ventilation control devices are considered in evaluating and determining the potential air paths and pressure changes. The pathways can start from any locations, such as intake, exhaust, or a fan branch. It can be used to assist in designing and managing the advanced mine ventilation systems, such as VOD systems, and determining which fan can efficiently supply the air volumes required in specified locations.

The program component of pathway mapping has been developed in such a way that it can be run independently in the background of other applications. In other words, the tool of pathway mapping can be implanted in other programs or ventilation management systems to generate the structure tree and perform pathway mapping of airflow delivery to various production areas in underground mine ventilation systems. It could also be used to maximise the blast clearance and evaluate the dust conditions in the production areas.

\section{References}

Hardcastle, SG, Kocsis, C \& O'Connor, D 2006, 'Justifying ventilation-on-demand in a Canadian mine and the need for process based simulations', Proceedings of the 11th U.S./North American Mine Ventilation Symposium 2006, in JM Mutmansky \& RV Ramani (eds), Taylor and Francis Group, London, pp. 15-27.

Kocsis, C, Hardcastle, SG \& Li, GG 2011, Ventilation-on-demand evaluation - Model development at Nickel Rim South Mine, Xstrata Nickel - CAF initiative, CANMET-MMSL Report 11-029(CR), Natural Resources Canada.

Li, GG, Kocsis, C \& Hardcastle, SG 2009, '3D-CANVENT - an integrated computer package for simulating underground mine ventilation systems', Proceedings of the 18th International Symposium on Mine Planning and Equipment Selection, in RK Singhal, A Mehrotra, K Fytas \& H Ge (eds), The Reading Matrix Inc., Irvine, pp. 513-521.

McPherson, MJ 1993, Subsurface Ventilation and Environmental Engineering, Chapman and Hall, London. 